\title{
Ethical Considerations in Teaching
}

\section{Self-Determination: Challenges in Rural Special Education ${ }^{1}$}

\author{
Tammy L. Smith \\ Campbell County Public Schools \\ Rustburg, VA \\ Julia F. Beyer \\ Edward A. Polloway \\ Lynchburg College \\ J. David Smith \\ University of North Carolina-Greensboro \\ James R. Patton \\ University of Texas at Austin
}

\begin{abstract}
The development of self-determination skills in students with disabilitics is a priority in special education. Its importance is particularly significant for students who are attcnding schools in rural areas. Instruction in self-determination also raises important ethical questions. Using a model developed by Bredberg and Davidson (1999), four foundational elements in ethics are explored with reference to selfdetermination: justice, respect for cconomy, beneficence, and non-maleficence. Considerations for providing instruction in these skills are highlighted and the challengcs of doing so in a rural setting are addressed.
\end{abstract}

\section{Ethical; Considerations in Teaching Self-Determination: Challenges in Rural Special Education'}

Self-determination is a core concern in special education. It encompasses a set of skills and behaviors that have 'been characterized as self-regulatory, goaloriented, and independent (Karvonen, Test, Wood, Browder, \& Algozzine, 2004). Its importance has been affirmed in research, in practice, and in the number of articles published on this subject. Smith, Polloway, Smith and Patton (2007) recently addressed this topic by exploring the limited attention given to the connection between what are deemed ethical teaching practices and the focus on self-determination. This paper expands and focuses this work on the unique challenges in providing special education in rural settings.

The research literature commonly identifles four key component of self-determination: the ability to act autonomously; the capacity to self-regulate behaviors; the ability to act in an empowered way; and the ability to act in a self-realizing manner (Palmer \& Wehmeyer, 1998; Stancliffe, Abery, Springborg, \& Elkin, 2000; Wehmeyer, Field, Doren, \& Mason, 2004; Wehmeyer, Kelchner, \& Richards 1996). Collectively these behaviors or skills enhance one's ability to make choices in one's best interests. Research has confIrmed that many persons with disabilities lack key skills in this area (e.g., Wehmeyer \& Palmer, 2003).

Instruction in self-determination has parallel ethical implications as well. While all persons who have professional or personal relationships with individuals with disabilities have a responsibility to uphold and encourage self-determination, special education teachers have a unique role. If they do not realize that instruction should be initiated early in a student's educational career and subsequently should become an integral part of a student's transition services, the implications can be significant (Smith et al., 2007).

Considerations of self-determination instruction, and the potentially ethical aspects of this instruction, are also important to consider within the context of the school and community settings in which instruction takes place. In this regard, addressing specifIc ethical issues that may impact successful educational practice in this domain that relate to rural settings is critical.

Defining rural is the United States is a difficult task due to its complexity; that is, no single attribute can characterize all rural places. The most commonly used definition is the U.S. Census Bureau classification. other defInitions include metropolitan status codes, urban-rural continuum codes, metro-centric locale codes, urban-centric locale codes, and core-based statistical areas (Rural Policy Research Institute, 2006).

All of these definitions generally classify rural places based on population size and density, level of urbanization, and adjacency relationship to an urbanized area (Rural Policy Research Institute, 2006). However, each definition applies these characteristics differently, which may result in contradictory results, and have serious implications for the challenges faced by many rural schools. Further, at the federal level different agencies use different definitions depending on the 
intended purpose. For example, the National Center for Education Statistics (NCES) describes three systems for classifying rural schools and districts: rural-urban continuum codes, metropolitan status codes, and locale codes. NCES also uses metropolitan status codes and locale codes to classify rural schools and districts (Arnold et al., 2007). Given the complexities of definitional issues, the discussion in this paper utilizes the term "rural" in its common sense use rather than according to specific definitions.

The purpose of this article is to examine selfdetermination and the related ethical issues in the context of rural special education. First, the article addresses the impact of self-determination on the lives of individuals with disabilities. Second, it considers how to determine what is ethical in teaching self-determination by using a four-prong test. Third, attention is focused on key issues related to self-determination instructional programs that are particularly relevant to educational practice in rural settings. The article concludes with a discussion of issues that rural teachers must address when dealing with self-determination instruction in an ethical manner.

\section{Self-Determination for Persons with Disabilities}

A growing research base has identified important aspects of self-determination in the lives of individuals with disabilities and has related it to educational practices. Several studies identify key aspects of selfdetermination. Wehmeyer and Palmer (2003) studied the impact of self-determination on the lives of 94 students with disabilities (in the categories learning disabilities or mental retardation) three years after they graduated from high school. At graduation, they had the students complete an initial survey in which they collected self-determination data, and they then followed up with the students after one and three years. They reported at follow up that students with higher levels of self-determination at graduation were more financially independent (e.g., able to maintain a checkbook, able to pay for groceries) and also were able to access jobs which allowed them to secure benefits like sick leave, medical insurance, and vacation (Wehmeyer \& Palmer, 2003).

Another aspect of self-determination was explored by Palmer and Wehmeyer (1998) when they evaluated the impact of hopelessness on self-determination in a study of 429 students with cognitive disabilities who ranged in age from 10 to 19 . They found that those who were identified with mental retardation had the highest hopelessness scores and that they were least empowered. Palmer and Wehmeyer noted several reasons why it was more likely that these particular students had the lowest scores including the lack of choice they had to exercise in their lives and their restricted learning environment (mostly in selfcontained classrooms).

Stancliffe et al. (2000) examined self-determination and personal control levels in the decision-making of persons with mental retardation in residential facilities as related to the type of guardian that each person had been appointed. As the researchers pointed out, one key characteristic of self-determination is the ability to exert control over one's own life. The respondents either had a conservator or guardian or they had been making their own decisions. Persons without a court-appointed conservator or a guardian exerted the most control over their own lives. Those with a court-appointed conservator were next in terms of exerting control in their lives. Those with guardians expressed the lowest levels of control. The authors also noted the level of disability had less effect on self-determination of personal control than did the type of guardianship.

Self-determination is an important skill that persons with disabilities must acquire. Thus, a persuasive argument can be made for the importance of selfdetermination training and education for persons with disabilities (Smith et al., 2007). An important issue then becomes how to make ethical choices concerning the nature of instruction in self-determination.

\section{Ethical Model for Teaching Self- Determination}

Determining how to measure ethical behavior in any context is a difficult task. Greer (1988) examined the multiple ways to look at ethics as applied to special education. For example, in the first way, some individuals use an ethical construct that is based on the notion that there is a universal law. A second way to make ethical arguments is to look at ethics as a moral code. A third way is to base them on relationships with people, that is, the primary focus should be on putting people first, and not treating a person as a means to an end. Paul, French, and Cranston-Gingras (2001) specifically discussed ethics and special education. They noted that it is vital to realize that ethics must not only be discussed but that special educators need to come to a firm understanding that ethics involve responsibility and responsible decision making.

Consistent with Smith et al. (2007), the concept of ethics is considered herein within the context of a fourprong test to assess what is or is not ethical. These four prongs of justice, respect for autonomy, beneficence, and non-maleficence are foundational elements when making an ethical argument (Bredberg \&Davidson, 1999). Justice refers to "fairness" and concerns the assumption that one group will not be either advantaged or disadvantaged relative to another group. Respect for autonomy refers to a respect for the independent personhood of another. Beneficence refers to working for the benefit of another (e.g., working for 
the benefit of another student). Non-maleficence refers to not causing harm to another person.

When self-determination instruction is considered within the framework of Bredberg and Davidson (1999), the initial issue (or prong, in their terms) is justice. Is it fair to not teach and help students to become self-determined? Consistent with the extant research (e.g., Myers \& Eisenman, 2005; Palmer \& Wehmeyer, 1998 Stancliffe et. al, 2000; Wehmeyer \& Palmer, 2003; Wehmeyer \& Schwartz, 1998), the acquisition of self-determination skills can improve adult life outcomes (e.g., salary, benefits, and quality of life). Bredberg and Davidson (1999) concluded that "a child's right to participate in schooling was not subject to qualification or differentiation. It was not earned, nor was it bestowed as an act of charity. It was objectively, a right, situated in the child's person. The teacher did not regard the child's placement as within a hierarchy, educational entitlement; she worked at realizing an entitlement" (p. 6).

The second prong is respect for autonomy. Selfdetermination instruction enables persons to exercise more control of their lives. This often creates challenges for teachers because, as Bredberg and Davidson (1999) noted "teachers were not unaware of the potential conflicts between their recognition of students' autonomy and concerns for their best interests. . . They recognized the obligation of responsible adults to make decisions in children's interest, even if those decisions went against the immediate wishes of the child" (p. 7). Thus, while the decision to teach self-determination may be made by a responsible adult, the outcome of the instruction should enable individuals to make future choices for themselves (Smith et al., 2007).

Bredberg and Davidson (1999) indicated that benefIcence (the third prong) was a primary ethical principle governing the actions of teachers of individuals with disabilities. They noted that "the obligation to choose the best course of action to serve the child's best interest is not ... an individual disposition but a mandate to be shared by everyone involved with a child's care and which demands the achievement of consensus among them" (p. 5). Not only does self-determination improve the likelihood of being treated more equally in society, it also enhances other adult outcomes (Smith et al., 2007).

The fourth prong, non-maleficence, addresses whether or not teaching self-determination does. no harm. Snilansky (1997) noted that a critical principle is to ensure that no harm comes to the individual for whom instruction is being provided. Because research indicates that self-determination improves life outcomes, it follows that failing to teach these skills can not only cause harm, but may also increase the probability of injustice, potentially leading to being denied or losing personal freedom (Smith et al., 2007).

\section{Instructional Challenges in the Context of Rural Special Education}

\section{General Considerations}

What is the status of self-determination as an instructional priority? Karvonen et al. (2004) reported that $75 \%$ of teachers at the middle and secondary levels rated self-determination skills as important, while only $55 \%$ confirmed that those goals actually were reflected in IEPs. When Wehmeyer and Schwartz (1998) examined 895 IEPs, they found that none included selfdetermination skills in transition goals. Additionally, Mason, Field, and Sawilowsky (2004) polled teachers and administrators and found that only $8 \%$ reported satisfactorily addressing self-determination goals with students in their IEPs.

These discouraging data are of concern given the ethical and programmatic arguments that can be posited that teachers should include self-determination skills within the curriculum for students with disabilities. The absence of self-determination goals may be due to the fact that teachers receive limited preparation concerning on how and when to assess and these skills and what should be included in the curriculum (Smith et al., 2007). A key concern, therefore, is how teachers learn to make selfdetermination a focus of instructional. Wehmeyer (2002) summarized the skills and knowledge needed as follows: learning to set personal goals; learning to solve problems that may prevent a person from reaching goals; making good choices consistent with interests and preferences; learning to participate in decisions that impact life; learning to self-advocate; learning to create a plan to achieve goals; and learning to self-regulate daily actions.

Wehmeyer (2002) identifIed age-appropriate activities to guide the curriculum for persons with disabilities. Key skills can be infused into the curriculum in the early elementary grades through activities that provide opportunities for choice making, allowing the child to exert control. At the upper elementary and middle school levels, he encouraged decision making as the added component of analyzing options and the benefits and drawbacks of each choice. Students should also be encouraged to set personal and educational goals and take steps to achieve those goals. In high school, students should make day-to-day decisions and set their own academic and post-school goals. one key aspect to be stressed is the connection between daily activities and long-term outcomes. Factors that have been noted in successful programs are: teachers making sure students made informed choices; students being given a range of options; and teachers occasionally disagreeing with their choices-forcing the students to think for themselves (Smith et al., 2007).

A critical area is student participation in planning 
(Karvonen et al., 2004). Toward this end, Bassett and Lehman (2002) developed a resource that provides teachers with ways to include students in a variety of conferences that affect their lives and require key selfdetermination skills. These practical ideas focus on student-led conferences, student-centered planning sessions, and student-directed meetings.

Myers and Eisenman (2005) explored the concept of student-led IEP meetings. In order for a student to lead her own meeting she must: have a clear idea of what she wants in life; take responsibility for educational and life choices; and serve as an advocate for herself. Clearly the idea of having a student-led IEP is in line with the ethical arguments being raised for selfdetermination instruction. If students are unable to represent their ideas or use poor judgment, however the team must ensure that the meeting does not result in detriment to the child. The goal is to provide opportunities for students to become more selfdetermined, not simply given freedoms that they are unable to manage (Myers \& Eisenman, 2005; Smith et al., 2007).

An often overlooked area in the discussion on selfdetermination instruction is assessment. A number of informal instruments have been developed that teachers can use to identify skill areas (see Clark, Patton, \& Moulton, 2000). Noting that a comprehensive assessment of transition needs should be conducted in the early stages of the transition process, Clark and Patton (2006) included self-determination as a major domain in their Transition Planning Inventory to ensure that this important area was not overlooked during assessment and planning.

\section{The Rural Context}

In considering the special challenges of emphasizing self-determination instruction in rural settings, and while doing so, focusing on the ethical aspects of that instruction, a number of considerations emerge having to do with the characteristics of rural areas. Certainly, it can be argued that the importance of self-determination as well as the principles of ethical decision-making are not unique to urban, suburban, or rural areas. Rather, what makes the challenge unique is the nature of the rural community and/or school environment. Therefore, this suggests a series of issues that are cogent to the question of being able to provide quality educational programs in this important domain.

First, rural America is becoming more diverse. About a third of the growth in rural areas is a result of international migration. This change creates a challenge because most rural schools are unaccustomed and unprepared to work with English Language Learners (Beaulieu \& Gibbs, 2005). Public schools in rural areas experience great difficulty filling teacher vacancies in the fields of English as a second language and foreign languages (Provasnik, Kewal, \& Coleman, 2007). Further, racial/ethnic minorities account for a smaller percentage of public school teachers in rural schools than in schools in all other locales. Two implications emerge from this trend. First, teaching selfdetermination will be particularly problematic as the population becomes diverse in a way that mirrors societal transformations that have occurred in more urban settings. Second, to the extent that selfdetermination instruction has a cultural context, there are limited reasons to be confident that many students in rural areas will be taught by individuals who have had similar cultural experiences.

A second consideration relates to the impact of enrollment patterns. In 2005 the percentage of public rural schools reporting severe under-enrollment was greater than in all other locales (Provasnik et al., 2007). Further, Provasnik et al. (2007) reported that student enrollment in rural schools was only one-fifth of all public school students. Decreasing enrollment patterns often relate to financial stressors in building school budgets. While the research summarized above underscores the importance of self-determination instruction, this emphasis may not compete well when budgets are tight and the focus is rather on increasing reading and mathematics scores.

A third consideration is that of student success in secondary school success and adult outcomes. While the importance of self-determination instruction begins at the elementary level, in reality, the curricular focus becomes far more significant for older students. Further, the completion of a student's educational career provides evidence of the success of educators in teaching specific skills and instilling the importance of self-advocacy and of personal choice. Therefore, it is instructive to consider that in 2002-03 the average freshman-to-graduation rate for public high school students in rural areas was lower than in cities and suburban areas (Provasnik et al., 2007). A larger percent of teenagers in rural than suburban areas were neither enrolled in school nor employed. This finding was likely related to the fact that the high school dropout rate among 16-24 year olds in rural areas was higher than in suburban areas. Lastly, college enrollment rates were generally lower in rural areas than in all other locales (Provasnik et al., 2007).

Rural settings tend to lack local job opportunities (Beulieu \& Gibbs, 2005). When major employers need an educated workforce, they tend to support quality schooling. However, when local employment opportunities are insufficient, well-educated persons tend to leave the area and the community then loses its investment in education (Carter, 1999). To the extent that the acquisition of self-determination skills has a positive impact on the ability of individual workers to make a significant contribution, it can have a parallel 
positive impact on the work environment for the community.

A fourth consideration has to do with the significant degree of poverty noted in rural areas. Provasnik et al. (2007) reported that $35 \%$ of students in rural areas were living at or below the poverty level as compared to $28 \%$ of students in suburban areas and that an increasing number of rural families are headed by single mothers and minorities, two population subgroups that are prone to economic disadvantage. Further, rural areas generally had lower median earnings than those in suburban areas (Provasnik et al., 2007). The low pay offered by many rural jobs means that parents may work more and thus might spend less quality time with their children. Highquality day, care may also be too expensive or too far away to be an option. Moreover, Beaulieu and Gibbs (2005) reported that rural children are less likely than their nonrural counterparts to have access to health services. The acquisition of self-determination skills could be argued to have a positive impact that could help students rise above poverty by; learning the skills they need to obtain a job and sustain a career.

A fifth consideration relates to the availability of a sufficient ,quantity of qualified teacher candidates for special education positions in rural areas. It is a common observation that teacher shortages are often a challenge faced by rural schools due to lower salaries and federal initiatives. In states with a large rural population, it is likely that special education teacher shortages are at or near the top of areas of need. The implications for quality instruction in unique areas such as self-determination can be critical and are likely to correlate with access to licensed teachers.

Further, new federal initiatives are placing significant demands on teachers. That is, teachers in, small rural districts often teach more than one academic' subject and may lack access to necessary professional development, yet the No Child Left Behind Act requires them to become highly qualified in each of those subjects in the same timeframe as teachers from. non-rural 'districts (Beaulieu \& Gibbs, 2005; The Rural School and Community Trust, 2006). Therefore, while we may speak of the ethical and pragmatic importance of self-determination instruction, there are a number of other competing practical issues that must be addressed by teachers in order to meet the standards to which they are being held by federal and state statute as well as to address their multiple instructional responsibilities within the school curriculum.

Finally, and in a summative fashion, we must consider school resources. Rural schools often do not receive the funding they need. Provasnik et al. (2007) reported that rural public schools received a smaller percentage of their revenues from federal sources than urban public schools. This may be why many school buildings in rural areas may have significant deferred maintenance and may lack the technology that would allow students access to distant resources (Beaulieu \& Gibbs, 2005). Further, Provasnik et al. (2007) reported that the access to instructional computers with Internet access was lower than in all other locales.

Resource shortages are significant for many reasons. For example, deferred maintenance may make the learning environment unsafe and less motivating to students. Further, shortages make it difficult to tailor programs to meet the student's needs, such as advanced placement, honors classes, and or special education classes (and, it might be added, specialized curricula such as in the area of self-determination) (University of Michigan, 2005). When the conditions in schools are not motivating students, they may experience learned helplessness and feel that they cannot succeed (University of Michigan, 2005). Moreover, access to the Internet has been identified to be a possible tool for reducing the negative effects of remoteness in some rural communities (Beaulieu \& Gibbs 2005).

\section{Discussion}

As Smith et al. (2007) emphasized, the existing literature supports the fact that special educators need to assess and teach self-determination because it makes a significant difference in the lives of their students. Self-determination skills are particularly critical in secondary special education, especially with regard to transition services (Johnson, Stodden, Emanuel, Luecking, \& Mack, 2002).

As Smith et al. (2007) content and this paper argues, teachers have an ethical responsibility to teach self-determination and to encourage its development in students with disabilities. Further they must make a determination on how to teach these skills. Choices should reflect the need to be fair, show respect for the humanity of the student, benefit the student, and not cause harm. Since self-determination instructional programs are relatively new, it is sometimes difficult to determine what will benefit a person with a disability. As Smith et al. (2007) concluded "research on several programs that have proven to be successful suggest that the best practices include programs with a well-defined curriculum, programs that involve students in their educational planning, and finally programs that make students take responsibility for choice-making in and out of the instructional environment" (p. 150).

For a variety of reasons, instruction in selfdetermination is not only problematic but also especially important for students growing up in rural communities and attending rural schools. Key considerations that have been identified within this manuscript include the impact of diversity, decreasing enrollment, poverty, and resource shortages. Diminished secondary school success and more restricted adult outcome are also important concerns. However, when the importance of instruction 
in self-determination skills instruction in special education is presented not only as empirically validated but also as an ethical responsibility, it provides a basis for teachers to not only examine their current teaching practices but also to ensure that these skills are being taught in an ethical manner.

\section{References}

Algozzine, B., Browder, D., Karvonen, M., Test, D. W., \& Wood, W. M. (2001). Effects Of interventions to promote self-determination fOr individuals with disabilities. Review of Educational Research, 71, 219-277.

ArnOld, M.L., Biscoe, B., Farmer, T.W., RobertsOn, D.L., \& Shipley, K.L. (2007). How the government defines rural has implications for education policies and practices. Southwest Regional Educational Laboratory and Edvance Research. Report No. 010. Retrieved on December 11, 2007 from http://ies.ed.gov/ncee/edlabs/regiOns/southwest/pdf/ REL_2007010.pdf.

Bassett, D. S., \& Lehman, J. (2002). Student-focused conferencing and planning. Austin, TX: PrO-Ed.

Beaulieu, L. J., \& Gibbs, R. (2005). The role of education: Promoting the economic and social vitality of rural America. Mississippi, MS: Southern Rural Development Center, Mississippi State University. Retrieved on December 11, 2007 from http://srdc.msstate.edu/publications/ ruraleducation.pdf.

Bredberg, E., \& Davidson, I. (1999). Ethical reasoning used by teachers of children with severe and profound intellectual disabilities: A preliminary investigation. International Journal of Disability, Development, and Education, 46, 88-107.

Carter, C.S. (1999). Education and development in poor rural communities: An interdisciplinary research agenda. Charleston, WV: ERIC Clearinghouse on Rural Education in Small schoOls.

Clark, G. M., Patton, J. R., \& MOulton, L. R. (2000). Informal assessments for transition planning. Austin, TX: Pro-Ed.

Clark, G. M., \& Patton, J. R. (2006). Transition planning inventory (Revised edition). Austin, TX: Pro-Ed.

Greer, J. (1988). Means and ends. Exceptional Children, 54, 390-393.

Johnson, D. R., Stodden, R. A., Emanuel, E. J., Luecking, R., \& Mack, M. (2002). Current challenges facing secondary education and transition services: What research tells us. Exceptional Children, 68, 519-531.

Karvonen, M., Test, D., Wood, W., Browder, D., \& Algozzine, B. (2004). Putting self-determination into practice. Exceptional Children, 71, 23-41.

Mason, C., Field, S., \& Sawilowsky, S. (2004). Implementation of self-determination activities and student participation in IEPs. Exceptional Children, 70, 441-451.

Morris, J. (2001). Impairment and disability: Constructing an ethics of care that promotes human rights. Hypatia, 16(4), 1-16.

Myers, A., \& Eisenman, L. (2005). Student-led IEPs: Take the first step. Teaching Exceptional Children, 37(4), 52-58.

Palmer, S., \& Wehmeyer, M. (1998). Students' expectations of the

\section{Footnote}

Portions of this paper were adapted from Smith, T.L., Polloway, E.A., Smith, J. D., \& Patton, J.R. (2007). Sclf-dctcrmination for pcrsons with developmental disabilities: Ethical considerations for teachers. Education and Training in Developmental Disabilities, 42, 144-157.

future: HOpelessness as a barrier to self-determination. Mental Retardation, 36, 128- I 36.

Paul, J., French, P., \& Cranston-Gingras, A. (2001). Ethics and special education. Focus on Exceptional Children, 34(1), 1-26.

Provasnik, S. Kewal R. A., \& Coleman, M. M. (2007). Status of education in rural America NCES. Washington, DC: National Center for Education Statistics. Retrieved December 11, 2007 from http:// nces.ed.gOv/pubs2007/2007040.pdf.

Rural Policy Research Institute. $\left({ }^{2} 006\right)$. Defining rural: Definitions of rural areas in the U.S. Columbia, MO: Author. Retrieved November 27, 2007 from http://www.rupri.org/resources/context/rural.html.

The Rural School and Community Trust. (2006). Position paper on the reauthorization of NCLB: The rural perspective. Retrieved on November 27, 2007 from http://www.ruraledu.org/atf/cf/\%7BF4BE47E7FA27-47A8 B6628DE8A6FC0577\%7D/NCLB_rural.pdf.

SchalOck, R. L., \& Keith, K. D. (1993). Quality of life questionnaire manual. Worthington, OH: IDS Publishing.

Smith, T.L., Polloway, E.A., Smith, J. D., \& Patton, J.R. (2007) Self-determination for persons with developmental disabilities: Ethical considerations for teachers. Education and Training in Developmental Disabilities, 42, 144-157.

Smilansky, S. (1997). Should I be grateful to you for not harming me? Philosophy and Phenomenological Research, 57, 585-597.

Stancliffe, R., Abery, B., Springborg, H., \& Elkin, S. (2000). Substitute decision-making and personal control: Implications for self-determination. Mental Retardation, 38, 407-421.

University of Michigan. (2005). Rural education. Retrieved December 1, 2007 from http://sitemaker.umich.edu/butler.356/home

Wehmeyer, M. (2002). Self-determination and the education of students with disabilities. Reston, VA: Council for Exceptional Children, Information Center on Disabilities and Gifted Education. Retrieved April 14, 2005 from http://ericec.org/digests/e632.html

Wehmeyer, M., Field, S., Doren, B., \& Mason, C. (2004). Self-determination and student involvement in standards-based reform. Exceptional Children, 70, 413-425.

Wehmeyer, M., Kelchner, K., \& Richards, S. (1996). Essential characteristics of self-determined behavior of individuals with mental retardation. American Journal on Mental Retardation, 100, 632-642.

Wehmeyer, M., \& Palmer, S. (2003). Adult outcomes for students with cognitive disabilities three-years after high school: The impact of selfdetermination. Education and Training in Mental Retardation and Developmental Disabilities, 38, 131-144. 
Copyright of Rural Special Education Quarterly is the property of $A R E 5$ and its content may not be copied or emailed to multiple sites or posted to a listserv without the copyright holder's express written permission. However, users may print, download, or email articles for individual use. 